1,000 cases of Psoriasis, 1,000 Crohn's disease (CD) and 1,001 healthy controls. Deletion genotyping was performed using TaqMan RealTime-PCR assays. The deletion genotype frequencies in controls did not deviate from Hardy-Weinberg Equilibrium $(\mathrm{p}>.1)$. We found an association between KRT77 deletion and $C D$ risk $(p=0.03)$ and also a putative association with pustular psoriasis $(p<0.05)$. We also demonstrated that the KRT77 protein is expressed in the intestinal lumen and Peyers Patches in addition to the know skin expression.

Conclusion: Given the strong association between SpA and subclinical gut inflammation and barrier defects in IBD these findings suggest that KRT77 heterozygous deletions with dysregulated gut permeability may play a role in IBD and the wider SpA phenotype.

Acknowledgement: We would like to thank the clinical researchers and patients participating in the IMID Consortium for their collaboration Disclosure of Interests: Antonio Julià: None declared, Richard Cuthbert: None declared, Anton Glueck: None declared, Javier Gisbert: None declared, Eugeni Domènech: None declared, Maria Lopez Lasanta: None declared, Núria Palau: None declared, Helena Marzo-Ortega Grant/ research support from: Janssen, Novartis and Pfizer, Consultant for: AbbVie, Celgene, Janssen, Eli-Lilly, Novartis and UCB, Speakers bureau: AbbVie, Celgene, Janssen, Eli-Lilly, Novartis and UCB, Dennis McGonagle Consultant for: Lilly, Novartis UCB, Speakers bureau: Lilly, Novartis UCB, Sara Marsal: None declared

DOI: 10.1136/annrheumdis-2019-eular.7745

\section{FRI0360 ANALYSIS OF BLOOD MONOCYTE TRANSCRIPTOMES AND BONE MARROW SAMPLES OF PATIENTS WITH AXIAL SPONDYLOARTHRITIS REVEALS THEIR CHANGES RELATED TO ACTIVATION AND MYELOPOIESIS}

Fabian Karow ${ }^{1}$, Joachim Grün${ }^{2}$, Biljana Smiljanovic ${ }^{2}$, Denis Poddubnyy ${ }^{1}$, Ulrike Erben ${ }^{1}$, Elisabeth Kenngott ${ }^{1}$, Thomas Häupl ${ }^{2}$, Andreas Grützkau²,

Uta Syrbe $1 .{ }^{1}$ Charite, Berlin, Germany; ${ }^{2}$ Deutsches Rheumaforschungszentrum, Berlin, Germany

Background: Axial spondyloarthritis (axSpA) is characterized by inflammation within the axial skeleton. Previously, we observed preactivation of circulating monocytes of axSpA patients suggesting systemic immune activation apart from local skeletal inflammation.

Objectives: The aim of this study was to characterize systemic immune activation in axSpA by analyzing axSpA-specific monocyte transcriptomes and changes in myelopoiesis.

Methods: We performed transcriptomic analyses using GeneChip HGU133 Plus2.0 arrays of CD14+ monocytes isolated from peripheral blood of 25 HLA-B27+ axSpA patients and 10 healthy controls (HC). 10 patients were classified as non-radiographic axSpA (nr-axSpA) and 15 patients as ankylosing spondylitis (AS). Robust Multichip Averaging Algorithm normalization and high performance chip data analysis were used to select differentially expressed transcripts that define 1) axSpA-geneexpression profile and 2) profile that discriminates $\mathrm{nr}$-axSpA from AS patients. Functional analysis of significant IDs was performed with Gene ontology $(\mathrm{GO})$ and reference transcriptomes that portrayed myelopoiesis in bone marrow and monocytes activation with TNF, LPS, IFN and G-CSF. Myelopoiesis in bone marrow was studied by immunohistology according to MPO and CD15 expression in sections from facet joints of AS patients and controls (CO) without skeletal disease ( $n=6 /$ group).

Results: Comparison between axSpA and HC monocyte transcriptomes identified 957 differentially expressed transcripts that allowed separation of both groups by hierarchical clustering. GO analysis revealed associations of axSpA related transcripts with cell-cell adhesion, immune responses including Ras-signalling, Jak-STAT-signalling, innate immunity. Comparison of axSpA related transcripts with reference transcriptomes identified overlap with late myelopoiesis, pronounced mobilisation of monocytes from bone marrow into blood triggered by G-CSF and weak TNF/LPS activation.

$\mathrm{Nr}$-axSpA and AS monocytes differed in 562 transcripts. GO analysis of these transcripts suggested alterations in mitochondrial activity, peptide transport and DNA repair. According to reference transcriptomes, profiles of nr-axSpA monocytes differed from those in AS by gene patterns of late myelopoiesis and G-CSF triggered mobilisation from bone marrow.

In histological analyses of bone marrow a significantly higher percentage of MPO+ cells indicative of left shifted granulopoiesis was found in AS vs. CO facet joints $(p<0.01)$.

Conclusion: AxSpA monocyte transcriptomes reflect weak immune activation by cytokine and/or LPS and premature release from bone marrow into blood. Bone marrow analysis shows a left shifted granulopoiesis in
AS - both of which may contribute to pathological immune response within the skeleton in axSpA.

\section{REFERENCE:}

[1] Conrad K, Wu P, Sieper J, Syrbe U. In vivo pre-activation of monocytes in patients with axial spondyloarthritis. Arthritis Res Ther. 2015 Jul 16:17:179. Doi: 10.1186/s13075-015-0694-2. PubMed PMID: 26178906

Disclosure of Interests: Fabian Karow: None declared, Joachim Grün: None declared, Biljana Smiljanovic: None declared, Denis Poddubnyy Grant/research support from: AbbVie, Merck Sharp \& Dohme, Novartis, Consultant for: AbbVie, Bristol-Myers Squibb, Janssen, Merck Sharp \& Dohme, Novartis, Pfizer, UCB Pharma, Speakers bureau: AbbVie, BristolMyers Squibb, Janssen, Merck Sharp \& Dohme, Novartis, Pfizer, Roche, UCB Pharma, Ulrike Erben: None declared, Elisabeth Kenngott: None declared, Thomas Häupl: None declared, Andreas Grützkau: None declared, Uta Syrbe: None declared DOI: 10.1136/annrheumdis-2019-eular.8051

\section{FRI0361 INNATE VERSUSADAPTIVE IL-17A PRODUCING CELLS IN AXIAL SPONDYLOARTHRITIS}

nicolas rosine ${ }^{1}$, Surya Koturan ${ }^{1}$, Hanane Yahia ${ }^{1}$, Claire Leloup ${ }^{1}$, Elisabetta Bianchi ${ }^{1,2}$, Corinne Miceli Richard ${ }^{1,2} 3^{2}$, Lars Rogge ${ }^{1,2}{ }^{1}{ }^{1}$ Institut Pasteur, Immunoregulation unit, Immunology department, Paris, France, ${ }^{2}$ Unité Mixte de Recherche, Institut Pasteur/AP-HP Hôpital Cochin, Paris, France; ${ }^{3}$ Hôpital Cochin. Assistance Publique - Hôpitaux de Paris, Department of Rheumatology, Paris, France

Background: IL-17A-inhibition has been very successful in AxSpA but the cell populations targeted by this new therapeutic remain unknown. This question is relevant because the recent failure of anti-IL-23 in AxSpA demonstrated that IL-23-independent IL-17-producing cells may be of particular relevance for $\mathrm{SpA}$ pathogenesis. Some data from literature sug gests the involvement of MAIT, $\gamma \delta \mathrm{T}$, and neutrophils as IL-17A producing cells in $\mathrm{AxSpA}(1-3)$. However, even though they may be responsible for IL-17A-mediated inflammation, it is still unclear which is the major IL-17A-producing cell population in this disease.

Objectives: To assess and compare gene expression profiles of neutrophils, MAIT, $\gamma \delta, \mathrm{CD} 4+$ and $\mathrm{CD} 8+\mathrm{T}$ cells from AxSpA patients.

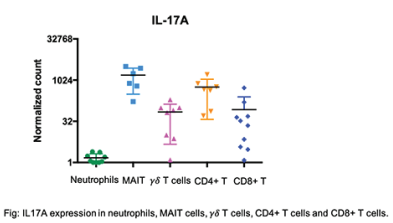

Methods: We recruited 5 healthy donors and 10 patients with a diagnosis of AxSpA according to the ASAS criteria. We compared the gene expres sion profiles of 5 sorted cell populations: 3 innate cell populations (neutrophils, MAIT and $\gamma \delta \mathrm{T}$ cells) and 2 adaptive cell populations (CD4+T and CD8+T) after cell stimulation by PMA + A23187 (calcium ionophore) $+\beta 1,3$ glucan (extracted from Aspergillus fumigatus hyphae). Published data suggested that neutrophils stimulation by Aspergillus fumigatus induces IL-17A production by these cells(4). For each of these cell populations, cytokine production and the expression of a panel of 755 genes (Autoimmune discovery panel from Nanostring including 43 genes for which a polymorphism was associated with AS) were assessed. Patient and control groups were compared with a Mann-Whitney test and com parison of cell populations was performed by a multigroup comparison. Results: There was no significant difference between patients and controls regarding gene expression profile of neutrophils, $\gamma \delta \mathrm{T}, \mathrm{CD} 4+\mathrm{T}$ and $\mathrm{CD} 8+\mathrm{T}$. We observed that 34 genes were differentially expressed between patients and controls in MAIT cells $(p=0.03, q=0.1)$. In particular, $\mathrm{T}$ cell activation genes (TBX21, $A H R, Z A P 70)$ and cell interaction genes (ITAG6, CTNNB1, ICAM2, ITGB2, SELL) were decreased in patients. Among AxSpA patients, MAIT cells were those significantly showing the highest level of IL-17A expression. IL23R and RORC were also more expressed by MAIT compared to others cell populations. IL 17A expression was very low in neutrophils but we observed that 18 out of the 43 AS associated genes were mainly expressed by neutrophils ( $p$ 
$<0.05, q=0.02$ ), supporting the idea that they should be involved in the pathophysiology of the disease.

Conclusion: These preliminary data confirm that the innate immune cells could play an important role in AxSpA. MAIT cells are at the forefront of the expression of IL-17A before $\gamma \delta \mathrm{T}, \mathrm{CD} 4+\mathrm{T}$ and CD8+T. Neutrophils do not appear to participate in the production of $\mathrm{IL}-17 \mathrm{~A}$, but the high expression of AS linked genes in these cells suggests their involvement in $\mathrm{AxSpA}$.

\section{REFERENCES:}

[1] Appel $\mathrm{H}$, et al. Analysis of $\mathrm{IL}-17(+)$ cells in facet joints of patients with spondyloarthritis suggests that the innate immune pathway might be of greater relevance than the Th17-mediated adaptive immune response. Arthritis Res Ther. 2011

[2] Kenna TJ, et al. Enrichment of circulating interleukin-17-secreting interleukin-23 receptor-positive $\gamma / \delta$ T cells in patients with active ankylosing spondylitis. Arthritis Rheum. 2012

[3] Gracey E, et al. IL-7 primes IL-17 in mucosal-associated invariant T (MAIT) cells, which contribute to the Th17-axis in ankylosing spondylitis. Ann Rheum Dis. 2016

[4] Taylor PR, et al. Activation of neutrophils by autocrine IL-17A-IL-17RC interactions during fungal infection is regulated by IL-6, IL-23, ROR $\gamma \mathrm{t}$ and dectin-2. Nat Immunol. 2014

Disclosure of Interests: nicolas rosine: None declared, Surya Koturan: None declared, Hanane Yahia: None declared, Claire Leloup: None declared, Elisabetta Bianchi: None declared, Corinne Miceli Richard Grant/ research support from: MSD, Pfizer, AbbVie, Biogen, UCB, Novartis, Consultant for: Abbvie, Novartis, BMS, Lars Rogge: None declared DOI: 10.1136/annrheumdis-2019-eular.6245

\section{FRI0362 HIGH-DIMENSIONAL MULTIPARAMETRIC CHARACTERIZATION OF THE REGULATORY T CELLS LANDSCAPE IN SPONDYLOARTHRITIS}

Davide Simone, India Brough, Liye Chen, Frank Penkava, Anna Ridley, Hui Shi, Hussein Al Mossawi, Paul Bowness. NDORMS, University of Oxford, Oxford, United Kingdom

Background: The Spondyloarthritides $(\mathrm{SpA})$ are immune-mediated conditions characterised by spinal and joint inflammation. The pathogenic role of Th17 lymphocytes has been shown by multiple studies but few reports exist on the phenotype of regulatory $T$ cells (Tregs) and their role in the course of the disease. Studying Tregs is particularly challenging because of their heterogeneous phenotype and potential plasticity at the site of inflammation. Given the complexity of the Treg landscape, a multi-dimensional approach, including both protein and gene analysis, offers novel mechanistic insights that can be leveraged to develop new treatments.

Objectives: 1) To describe the Treg phenotype in SpA patients compared to controls. 2) To identify differential expression of markers, such as trafficking molecules or co-inhibitory molecules, within Tregs at the inflammatory site. 3) To define the gene expression landscape in Tregs in the peripheral blood and synovial fluid in patients with active SpA.

Methods: A total of 61 patients with SpA (38 with Ankylosing Spondylitis (AS), 23 with Psoriatic Arthritis (PsA)) and 16 age-matched healthy controls were recruited. Peripheral blood (PB) and paired synovial fluid (SF) mononuclear cells $(n=8)$ were also analyzed. Isolated mononuclear cells were stained with 3 multicolor flow cytometry panels, including a total of 35 surface and intracellular protein markers. Manual gating was done in parallel with unsupervised data analysis using FlowSOM and SPADE. Cells from blood and synovial fluid from three treatment-naive PsA patients were isolated and their RNA sequenced at a single cell level with the 10x Genomics platform.

Results: Whereas no major difference in the Treg frequency was observed comparing the $\mathrm{PB}$ of $\mathrm{SpA}$ patients and healthy controls, in the SF we observed a higher Treg frequency, with a striking prevalence of the memory (CD45RA-) compartment (mean: 11.7 vs $4.7 \% ; \mathrm{p}=0.01$ ) and a higher expression of Foxp3 $(p=0.04)$. Trafficking markers demonstrated considerable heterogeneity, as visualized on SPADE analysis, mirroring the classification of $\mathrm{T}$ helper cells, but little difference in terms of relative frequency compared to healthy controls. Within the Treg compartment we identified populations of Helios-negative Th17-like cells able to secrete higher levels of $\mathrm{IL}-17 \mathrm{~A}$ (mean: 2.8 vs 1.2\%; $\mathrm{p}=0.02$ ) while expressing normal levels of Foxp3; and putative regulatory CD8+ $\mathrm{T}$ cells expressing classical Treg features (Foxp3, CTLA4).

The analysis of the single cell transcriptomic data confirmed a high degree of heterogeneity, both in the SF and the PB, with consistent findings across patients. Unsupervised clustering identified different subsets that share a core of regulatory transcripts, onto which additional programs are added, including a very distinct Th17-like module. Of note various Treg subsets express preferentially different co-inhibitory genes, suggesting a functional specialization

Conclusion: High-dimensional immunoprofiling in SpA patients shows normal frequency of Tregs in the PB, but increased Tregs with activated phenotype in the inflammatory site. The presence within the Treg population of Th17-like and CD8+ populations are intriguing preliminary findings that require further evaluation. Preliminary transcriptomic analysis confirms the presence of specialized subsets within the Treg compartment.

Disclosure of Interests: Davide Simone: None declared, India Brough: None declared, Liye Chen: None declared, Frank Penkava: None declared, Anna Ridley: None declared, Hui Shi: None declared, Hussein Al Mossawi Grant/research support from: UCB, Paul Bowness Grant/ research support from: Merck, GSK, Celgene DOI: 10.1136/annrheumdis-2019-eular.1749

\section{FRI0363 AUTOANTIBODIES TO THREE NOVEL PEPTIDES IN EARLY AXIAL SPONDYLOARTHRITIS IN TWO INDEPENDENT COHORTS}

Dana Quaden ${ }^{1}$, Patrick Vandormael ${ }^{1}$, Piet Geusens ${ }^{1,2,3}$, Johan Vanhoof ${ }^{2}$, Kurt de Vlam ${ }^{4,5}$, Veerle Somers ${ }^{1} .{ }^{1}$ Hasselt University, Biomedical Research Institute, Diepenbeek, Belgium; ${ }^{2}$ ReumaClinic, Genk, Belgium; ${ }^{3}$ Maastricht University Medical Center, Internal Medicine, Rheumatology, Maastricht, Netherlands ${ }^{4}$ University Hospitals Leuven, Division of Rheumatology, Leuven, Belgium; ${ }^{5}$ University Hospitals Leuven, Skeletal Biology and Engineering Research Center, Department of Development and Regeneration, Leuven, Belgium

Background: Diagnosis of axial spondyloarthritis (axSpA) is challenging since clinical manifestations, such as inflammatory back pain, peripheral arthritis, enthesitis and inflammatory bowel disease, often overlap with other disorders. Current laboratory markers for axSpA, Human Leukocyte Antigen (HLA)-B27 and C-reactive protein (CRP) are not sufficiently specific for diagnosis. Despite being considered a "seronegative" disease, emerging evidence supports the involvement of antibodies in axSpA. In order to identify novel autoantibodies in axSpA patients, we recently screened an axSpA cDNA phage display library for reactivity with immunoglobulin $G$ ( $\lg G$ ) antibodies in plasma of early axSpA patients. This resulted in autoantibodies to 9 novel University of Hasselt (UH) axSpA peptide targets, corresponding to fragments of known proteins and novel lineair peptides.

Objectives: The aim of this study was to determine the diagnostic potential of autoantibodies to the 9 novel $\mathrm{UH}$ axSpA peptides in axSpA patients and controls from 2 independent cohorts.

Methods: Using enzyme-linked immunosorbent assays (ELISA), presence of antibodies to the $9 \mathrm{UH}$ axSpA peptides expressed on phage particles was determined in 76 early axSpA patients, 75 chronic low back pain patients (LBP), 60 early rheumatoid arthritis patients (RA) and 94 healthy controls $(\mathrm{HC})$ from the $\mathrm{UH}$ cohort. Antibody reactivity was further validated in 174 patients from the Leuven Spondyloarthritis (Biologics) Cohort ((Bio)SPAR), including 79 early axSpA patients.

Results: Antibody reactivity against at least one of 9 novel $\mathrm{UH}$ axSpA peptides was found in $54 \%(41 / 76)$ of early axSpA patients, $26 \%(24 / 94)$ of $\mathrm{HC}(p=0.0002), 39 \%(29 / 75)$ of LBP $(p=0.0731)$ and $38 \%(23 / 60)$ of RA patients $(p=0.0845)$ from the $U H$ cohort, as compared to $43 \%(74 /$ 174) of the axSpA patients from the (Bio)SPAR cohort. By combining the three $\mathrm{UH}$ axSpA peptides with highest positive likelihood ratios (LR+) into a panel, antibodies against these 3 peptides were detected in $14.2 \%$ (22/ 155 ) of early axSpA patients from the combined UH and (Bio)SPAR cohorts and in only $5 \%(4 / 75)$ of persons with LBP $(p=0.0484)$, resulting in a specificity of $95 \%$.. The LR+ for confirming axSpA using antibodies to these $3 \mathrm{UH}$ axSpA peptides was 2.7 , which is the same as for the currently used laboratory marker CRP. Assuming a $5 \%$ pretest probability of axSpA in persons with LBP, a combination of the presence of inflammatory back pain $(L R+3.1)$ and a positive test result for the laboratory markers HLA-B27 (LR+ 9.0) and CRP (LR+ 2.5) provides a disease (posttest) probability of $79 \%$. When we added a positive test result for the presence of antibodies to the $3 \mathrm{UH}$ axSpA peptides (LR+2.7), posttest probability could be increased to $91 \%$

Conclusion: Antibodies to $3 \mathrm{UH}$ axSpA peptides were significantly more present in early axSpA patients compared to LBP and could provide a novel tool for objective diagnosis of a subset of axSpA patients.

Disclosure of Interests: Dana Quaden: None declared, Patrick Vandormael: None declared, Piet Geusens Grant/research support from: Research support, consultant and/or speaker fees from: Pfizer, Abbott, El 